\title{
Medisinsk fødselsregister i miljøovervåkingen - muligheter og begrensninger
}

\author{
Petter Kristensen ${ }^{1,2}$ \\ ${ }^{I}$ Avdeling for arbeidsmedisin og epidemiologi, Statens arbeidsmiljøinstitutt, Oslo \\ ${ }^{2}$ Avdeling for samfunnsmedisin og global helse, Institutt for helse og samfunn, Det medisinske fakultet, Universitetet i Oslo \\ petter.kristensen@stami.no
}

\begin{abstract}
SAMMENDRAG
Overvåking har vært en prioritert oppgave for Medisinsk fødselsregister helt siden starten i 1967. Denne oversikten dekker miljøovervåkingen, i første rekke arbeidsmiljø og ytre miljø. Overvåkingen har størst fokus på medfødte misdannelser, men dekker også andre skadelige utfall som oppdages ved fødsel eller i løpet av første leveår. Clustere, tilsynelatende uvanlige opphopninger i tid og/eller rom av skadeutfall, er sentrale i overvåking. Den systematiske overvåkingen foregår i stor grad i EUROCAT-nettverket, og er særlig egnet til å avdekke plutselige, utbredte, og/eller svært teratogene eksponeringsagens. Miljøovervåkingen kan også være $a d-h o c$ basert, enten proaktivt med oppfølging av skadeutfall under mistanke etter en miljøhendelse, eller reaktivt som en utredning av miljøårsaker etter observasjon av et på forhånd uventet cluster av sykdom eller skade. Som eksempler blir Medisinsk fødselsregisters rolle i oppfølging av Tsjernobylulykken i 1986 og Kvikksaken på 1990- og 2000-tallet gjennomgått. Akilleshælen i miljøovervåkingen er mangelfulle eksponeringsdata.
\end{abstract}

\section{Kristensen P. The Medical Birth Registry of Norway in environmental surveillance - possibilities and limitations. Nor J Epidemiol 2017; 27 (1-2): 41-46.}

\section{ENGLISH SUMMARY}

Surveillance by The Medical Birth Registry of Norway has been a prioritized task since the start in 1967. This presentation covers surveillance in the occupational and outer environment. Surveillance has primary focus on birth defects but encompasses also other adverse effects present at birth or during the first year of life. Clusters, apparent unusual increases in time and/or space of adverse events, are important in surveillance. Systematic surveillance is largely carried out in the EUROCAT network, and is particularly suited for discovering exposure agents that are sudden, widespread, and/or highly teratogenic. Ad-hoc environmental surveillance can be carried out in the aftermath of an exposure incident, searching for increases in adverse outcomes under suspicion, or as a search for causal explanations after observing unexpected clustering of adverse outcomes. I present examples of the two: investigations after Chernobyl, and examinations of clustering of birth defects among children whose fathers served on board the naval vessel KNM Kvikk. The Achilles heel of the Birth Registry's environmental surveillance is insufficient exposure data.

This is an open access article distributed under the Creative Commons Attribution Licence, which permits unrestricted use, distribution, and reproduction in any medium, provided the original work is properly cited.

\section{INNLEDNING}

Kunnskapen om at et stort antall medfødte misdannelser ble forårsaket av legemidlet talidomid var en viktig grunn til at Medisinsk fødselsregister (MFR) ble opprettet for 50 år siden [1-3]. Et formål med MFR skulle være overvåking for å forebygge og forhindre en ny, lignende katastrofe. Dette er senere nedfelt i Medisinsk fødselsregisterforskriften, hvor formålet, ved siden av årsaksrettet forskning, er å overvåke hyppighet av blant annet «avvikende fødselsvekt, lidelser, misdannelser og skader blant fødte og barn under ett år, fosterdød og dødsfall blant barn under ett år» [4]. Opplegg for å overvåke medfødte misdannelser og andre skadeutfall ble utarbeidet og tatt i bruk i løpet av fødselsregisterets første år [5], og senere raffinert i Rolv Terje Lies doktorarbeid [6]. Det var i utgangspunktet et spesielt fokus på spesifikke og i mange tilfelle sjeldne medfødte misdannelser. Internasjonalt samarbeid i overvåkingen var derfor naturlig. MFR bidro aktivt til dannelsen og utviklingen av International Clearinghouse for Birth Defects Monitoring Systems, og senere til nordisk og europeisk samarbeid gjennom henholdsvis Nordic Association of Medical Birth Registries (NOMBIR) og European Surveillance of Congenital Anomalies (EUROCAT) [3]. I de senere år har særlig samarbeidet i EUROCAT $[7,8]$ vært viktig.

På 1970- og 1980-tallet var det internasjonalt stor optimisme og tro på at epidemiologisk overvåking og forskning skulle kunne avdekke miljøårsaker til skadelige reproduksjonsutfall $[9,10]$. Det er naturlig å spørre om denne optimismen har slått til, og hvilken verdi MFR har hatt i miljøovervåkingen. I denne oversikten vil jeg forsøke å illustrere dette med et par eksempler. Disse eksemplene kan si oss noe om rammene MFR opererer under, om muligheter og begrensninger. Lærdommene vi kan trekke kan i sin tur være av nytte i fremtidig miljøovervåking, og på grunnlag av historien og eksemplene vil jeg fremme noen forslag. 


\section{MILJØOVERVÅKING - RAMMER}

Jeg vil avgrense miljøet til faktorer i arbeid og det ytre miljøet. Det betyr at legemidler og eksponering gjennom kosthold og individuell atferd faller utenfor $\mathrm{i}$ denne gjennomgangen. Avgrensningen er ikke skarp: Overvåking av effekter av plantevernmidler og persistente organiske forbindelser i fødevarer og drikkevann kan være i en gråsone, tobakksrøyking vil falle utenfor mens passiv røyking hører til det ytre miljøet eller arbeidsmiljøet. Det er heller ikke noen klar definisjon av hva som faller inn under overvåking. Spesielt kan avgrensningen mellom overvåking og forskning være uskarp [11]. Eksempler på forskningsprosjekter med et overvåkingsaspekt er studier av misdannelsers relasjon til drikkevann $[12,13]$ eller kraftlinjer [14,15]. Et klart utgangspunkt for MFRs oppfølging av Tsjernobyl-hendelsen var overvåking av følgene av utslippene, mens metodene i stor grad fulgte prinsippene for årsaksrettet forskning med a-priori-formulerte hypoteser [16,17]. Det er også eksempler på at overvåking genererer hypoteser som siden kan følges opp gjennom forskning. Skadeutfallene under overvåking i MFR inkluderer i henhold til forskriften [4] ikke bare medfødte misdannelser og kromosomavvik, men også mortalitet og vekstforhold i fosterlivet. Kjønnsratio (kjønnsfordeling) i grupper av nyfødte vil også være relevant. Overvåking basert på MFR er heller ikke avgrenset til arbeid som utføres av MFR i alle ledd, men inkluderer også tiltak der MFR er dataleverandør.

\section{MÅLET MEd OVERVÅKING}

Det er nyttig å vurdere resultater av overvåking opp mot hensikten. Grovt sett kan man si at resultatet kan være en avklaring at det ikke er en skadelig effekt («negativt» eller «grønt» resultat, den gode nyhet) eller en avklaring om at det er en skadelig effekt («positivt» eller «rødt» resultat, den dårlige nyhet). Ofte vil resultatet ligge i en mellomsone («non-negativt» eller «nonpositivt»). På sikt vil avdekking av en skaderisiko være bra fordi man da identifiserer noe som kan forebygges, mens resultater som ligger langt unna en positiv eller negativ avklaring er det største problemet fordi det ikke gir noen klar føring med hensyn til tiltak.

\section{TYPER AV OVERVÅKING}

Den epidemiologiske overvåkingen i MFR-regi er til dels en systematisk aktivitet over tid, som følger bestemte retningslinjer og kriterier. For medfødte misdannelser og kromosomavvik er dette en aktivitet som er samordnet internasjonalt gjennom EUROCATnettverket $[7,8,18]$. Overvåkingen i EUROCAT dekker 72 misdannelseskategorier med tidsregistrering i «moving windows» $\mathrm{i}$ et system som er best egnet til å avdekke plutselige, utbredte, og/eller svært teratogene eksponeringsagens [18]. Et eksempel er observasjonen av en tidsavgrenset økt forekomst av gastroschise (en defekt i bukveggen som fører til at bukinnhold blir lig- gende utenfor bukhulen), samsvarende med lignende funn $i$ andre vestlige land, men uten at man fant en forklaring i miljøet eller ellers [1]. Lie [19] gir flere eksempler. En systematisk overvåking kan også være knyttet opp til spesifikke miljøeksponeringer under mistanke. MFR har gjennomført slik overvåking ved kobling mellom MFR og andre nasjonale registre, for eksempel Folke- og boligtellingene (FoBT) med data på mors [20] eller foreldres [21] yrke.

En annen viktig del av overvåkingen er ad-hocbasert. Denne kan være proaktiv som en oppfølging av miljøeksponering etter hendelser («a causal hypothesis in search of a cluster») eller reaktiv etter observasjon av et sykdomscluster med eller uten mistanke til en bestemt årsaksforklaring i miljøet («a cluster in search of a causal hypothesis») [22].

Clustere (klynger) av utfall står sentralt i overvåking. Et cluster kan defineres som en tilsynelatende uvanlig opphopning i tid og/eller rom av et skadelig utfall, hvor «rom» ikke nødvendigvis betyr bosted men kan være yrke/arbeid/utdanning/fritid [21,22]. Et eksempel på miljøovervåking hvor man leter etter clustere i etterkant er tiltakene etter Tsjernobyl $[16,17]$. Det er flere eksempler på spontan observasjon av clustere hvor man i ettertid leter etter årsaksforklaringer. Det første som involverte MFR var clustring av perinatal død i Bømlo i 1981 [1]. Det best kjente eksemplet med deltakelse av MFR kan være Kvikksaken (https://no.m.wikipedia.org/wiki/Kvikk-saken). Et annet eksempel med uttalt mistanke til miljøet var clustring av reduksjonsdeformiteter blant fødte i Grenland og Rana, hvor oppfølgingen ble gjennomført $i$ en case-control studie [23]. Reproduksjonsutfall hos barn av kvikksølveksponerte tannlegeassistenter [24] kan ikke kategoriseres like klart som reaktivt siden clustermistanken i utgangspunktet gjaldt utfall hos kvinnene selv, mens mistanke om økt risiko hos barna kom sekundært.

\section{EKSEMPEL 1 - TSJERNOBYLSAKEN}

Det er interessant å observere at EUROCAT og MFR hadde en noe ulik overvåkingsstrategi etter Tsjernobylhendelsen i april 1986. EUROCAT la opp til overvåking og registrering av clustere med hovedvekt på kromosomanomalier og sentralnervøse misdannelser (før MFR sluttet seg til EUROCAT-nettverket i 1998) [25]. MFR hadde en mer ambisiøs oppfølging basert på kobling mellom en detaljert eksponeringsmatrise og MFR [16,17]. Eksponeringsmatrisen ble utarbeidet av Statens strålevern, hvor intern og ekstern dose ble tilskrevet alle landets kommuner på månedlig basis. Det ble ikke registrert positive assosiasjoner mellom strålingsdose og de primære utfallene medfødt katarakt, mikrocefali, liten hodeomkrets eller lav fødselsvekt, mens assosiasjonen med Down syndrom var negativ [17]. Antall registrerte svangerskap var noe lavere enn forventet, men det ble ikke registrert økning i svangerskapsavbrudd [16]. 


\section{EKSEMPEL 2 - KVIKKSAKEN}

Både fartøyet (https://no.m.wikipedia.org/wiki/KNM \%C2\%ABKvikk\%C2\%BB) og Kvikksaken (https:// no.m.wikipedia.org/wiki/Kvikk-saken) er registrert i Wikipedia. Dette kan være en indikasjon på at dette er den clustersaken med MFR-involvering som har hatt størst allmenn interesse. Dette var et typisk reaktivt cluster som angivelig startet med at to fedre som fulgte sine barn til kontroll på ortopedisk avdeling ved Haukeland sykehus tilfeldig møttes og fant ut at de hadde en felles historie med tjeneste på missiltorpedobåten KNM Kvikk. Foreldrene avklarte etter hvert at flere fedre med tjeneste på fartøyet hadde fått barn med medfødte misdannelser. Sjøforsvaret gjennomførte en omfattende utredning [26] hvor MFR tok del [27,28] for å avklare om radiofrekvente felt fra elektronisk utstyr om bord kunne være en forklaring på barnas skader. Det var rimelig avklart at barn av fedre som hadde tjenestegjort om bord KNM Kvikk hadde en høy forekomst medfødte misdannelser, men det ble ikke funnet grunnlag for å knytte dette opp mot elektromagnetiske felter eller andre eksponeringer om bord [26-28]. Misnøye med resultatet og mulig interessekonflikt ble uttrykt fra blant annet media og representanter for foreldrene og resulterte $i$ at en ny utredning, også den med deltakelse fra MFR, ble gjennomført av Statens arbeidsmiljøinstitutt på oppdrag fra Forsvarsdepartementet [29]. Resultatet av denne var ganske lik det forrige, og misnøyen la seg ikke. MFR deltok senere $\mathrm{i}$ et forskningsprosjekt på elektromagnetiske felt og reproduksjonshelse, finansiert av Forsvarsdepartementet. I en delstudie ble perinatalutfall blant personell i Sjøforsvaret assosiert med deres eksponering for radiofrekvente felt $\mathrm{i}$ arbeidet [30], og $\mathrm{i}$ en annen delstudie ble utfall registrert i MFR assosiert med fars yrkeseksponering for elektromagnetiske felt i ulike yrker og bransjer [31].

Misnøyen og uklarheten i Kvikksaken medvirket også til gjennomføring av oppfølgingsstudier uten deltakelse fra MFR. Det største av disse var HMS Sjøprosjektet, finansiert av Sjøforsvaret og gjennomført av Universitetet i Bergen [32]. Her ble data i stor grad basert på spørreskjema utfylt av personell i Sjøforsvaret [33] og eksponeringsdata fra tidligere [26] og oppdaterte [34] målinger av radiofrekvente felt. Flere utfall ble studert, blant annet medfødte misdannelser [35], kjønnsratio [36], fertilitet [36,37] og reproduksjonsutfall hos kvinnelig personell [38].

\section{DISKUSJON}

Et klart eksempel på at samordnet overvåking og forskning har forebygget helseskade er erkjennelsen av økt krybbedødrisiko ved mageleie, andre eksempler er legemidlet valproinsyre og mangel på vitaminet folsyre som årsak til nevralrørsdefekter [3,19]. De viktigste bidragene av overvåking i MFR-regi har dermed vært på andre områder enn arbeidsmiljø og ytre miljø. Man kan imidlertid hevde at avklaring av manglende risikoøkning kan være av like stor verdi som oppdagelsen av økt risiko. Mangel på clustring av medfødte misdannelser i den systematiske overvåkingen vil derfor bidra til å redusere bekymring i befolkningen. Dette kan blant annet gjelde mobiltelefoni eller andre eksponeringsfaktorer som har blitt ubikvitære i løpet av de siste tiårene. Resultatene som kom ut av undersøkelsene etter Tsjernobyl [16,17] eller svangerskapsutfall hos tannlegeassistenter [24] kan ha bidratt i samme retning.

\section{Begrensninger, miljoeksponering}

Mangelen på klare resultater i miljøovervåkingen kan også bero på metodiske begrensninger. Akilleshælen i miljøovervåkingen er manglende eller dårlig kvalitet på eksponeringsdata. Miljøovervåking krever miljødata. Slike data er nærmest fraværende i fødselsmeldingen. Et unntak er mors yrke ved fødselen som fra 1999 er inkludert i fritekst dersom mor ikke motsetter seg det. Arbeidet med yrkeskoding har vært planlagt men ikke fullført. Mangelen har vært løst ved å koble MFR til FoBT [20,21]. Mors bosted ved fødselen er en indikator som har vært nyttet til å karakterisere eksponering i miljøet, for eksempel i oppfølgingen av Tsjernobyl $[16,17]$. Misklassifisering når det optimale er å ha informasjon på oppholdssted i tiden rundt konsepsjonen ser umiddelbart ut til å være et lite problem. Misklassifiseringen kan imidlertid være mer alvorlig dersom gravide $\mathrm{i}$ høyeksponerte områder flytter nettopp for å unngå eksponering.

Koblingen av MFR til MoBa åpner muligheten for å få data på miljøeksponering [39]. I tillegg til utnytting $\mathrm{i}$ årsaksrettet forskning kan man tenke seg situasjoner hvor MoBa-foreldres selvrapporterte eksponeringer $\mathrm{i}$ yrke eller miljøforurensning eller til og med biomarkører kan benyttes i ad-hoc basert overvåking.

Den nasjonale forløpsdatabasen FD-trygd [40] er en kilde til informasjon som potensielt er av stor verdi. FD-trygd inneholder yrkesdata som antakelig vil være bedre egnet enn yrke i fødselsmeldingen eller FoBT fordi man kan identifisere yrket ved tidspunktet rundt konsepsjonen. FD-trygd inkluderer også bostedshistorie og vil derfor kunne være av større verdi enn bostedsdata i MFR ved overvåking etter fremtidige hendelser med likhetstrekk til Tsjernobyl. Permanent kobling av FD-trygd-data vil måtte godkjennes etter kriterier gitt i Helseregisterloven.

Overvåking av kjemiske stoffer i arbeidsmiljøet eller det ytre miljø som gir ekstra grunn til bekymring er vanskelig men sterkt ønskelig. Hit hører blant annet plantevernmidler og stoffer som er klassifisert som kreftfremkallende, mutagene eller reproduksjonsskadelige (CMR-stoffer). Gode eksponeringsdata for plantevernmidler er som regel ikke tilgjengelig, i tillegg brukes disse oftest i komplekse blandinger [41]. På ad-hoc-basis har landbrukstellingene i kombinasjon med detaljerte bruksregler for spesifikke plantevernmidler vært utnyttet til å undersøke mistanken om at fungicidet benomyl er en årsak til mangelfull utvikling 
av øyeanlegget (anoftalmi) [42]. På sikt er det mulig at regelverk med autorisasjon av yrkesbrukere og krav til sprøytejournal [43] kan utnyttes til ad-hoc-basert overvåking. Miljødirektoratets krav til dokumentasjon og regulering av stoffer som gir stor grunn til bekymring for helse og/eller miljø (subtances of very high concern; SVHC) [44] kan muligens bli av fremtidig verdi i miljøovervåking.

\section{Begrensninger, MFR- utfall}

Kvalitet på utfallsdata er en utfordring i overvåking. Dysmorfologisk kunnskap og vurdering vil være viktig for klassifisering og gruppering av misdannelser [45]. For misdannelser er ICD-10 klassifisering fra 1999 bedre egnet enn tidligere ICD-8 klassifisering. I den systematiske overvåkingen i EUROCAT-regi [7] følges et stort antall misdannelsesgrupper. I ad-hocbasert virksomhet vil det optimale være oppfølging av spesifiserte utfall under mistanke, for eksempel medfødt katarakt etter Tsjernobyl [16,17]. I mindre clusterutredninger vil imidlertid powerproblemer ofte tvinge frem analyse med brede grupperinger av heterogene utfall. Fullstendighet av registrering i MFR har spesielt vært diskutert $\mathrm{i}$ forbindelse med selektivt svangerskapsavbrudd ved Down syndrom [46] og enkelte kategorier av medfødte misdannelser [19]. Manglende registrering har også kommet i fokus i enkelttilfelle som Kvikksaken [27]. Endringer etter 1998 med systematisk registrering av tilstander diagnostisert $\mathrm{i}$ første leveår og diagnoser som gir grunnlag for abort [19] kan ha stor positiv betydning for overvåking.

Overvåking av befolkningens fekunditet er et tema av allmenn interesse på grunn av mistanken om skadelig effekt av miljøforurensning [47]. MFR-data er i dag ikke godt egnet til slik overvåking. Det er mulig at inkludering av enkle spørsmål ved første svangerskapskontroll [48] kunne være en løsning, selv om det ville være betydelige metodiske utfordringer [49].

\section{Hva kan gjores bedre neste gang?}

Utredningene i kjølvannet av Tsjernobylulykken $[16,17]$ var av stor verdi for å avklare risiko i Norge. Mulighetene for oppfølging av tilsvarende hendelser $i$ fremtiden vil i utgangspunktet være enda bedre, siden kvaliteten i registrering av medfødte misdannelser og svangerskapsavbrudd er bedre enn på 1980-tallet. Tilkobling av bostedshistorie i forløpsdatabasen FD-trygd
[40] ville gjøre karakteriseringen av eksponering enda bedre, og ville også kunne bidra til å klarlegge eventuelle atferdsendringer blant gravide som følge av en mistenkt miljøkatastrofe.

MFR la ned betydelige ressurser gjennom mange år for å bidra til avklaring i Kvikksaken. I etterpåklokskap er det betimelig å spørre om aktivitetene var optimale, og om noe kan læres for fremtiden.

Kvikksaken illustrerer godt at det kan være spesielle utfordringer med utredning av reaktive clustere [50,51]. Et viktig element er at risikooppfatningen hos ulike berørte parter kan påvirkes av det Sandman kaller «outrage factors» [52]. I Kvikksaken var den mistenkte eksponeringen usynlig, uvanlig sterk, og det var liten mulighet å unngå eller påvirke den. Det var snakk om alvorlige helseskader som gikk ut over uskyldige barn. Som tilfelle for mange tilsvarende saker $\mathrm{i}$ arbeidslivet vil det formelt og reelt være en asymmetri i makt og styrkeforhold mellom arbeidsgiver og arbeidstaker. I tillegg ble det reist mistanke til at Forsvaret hadde noe å skjule og at utredningene ikke foregikk på en uhildet måte. Alt dette åpnet for at risikooppfatningen hos foreldre, annet personell, allmennhet, forsvarsledelse og eksperter i utredningene kunne bli ulike. Et annet viktig element er at Poissonfordeling ikke er uniform, noe som kan bryte med intuitiv oppfatning av tilfeldighet: Det er høyst sannsynlig at det usannsynlige av og til vil opptre tilfeldig. Et tredje element som er særegent for reaktive clustere er at avgrensningen av nevneren (tid og rom), og av og til telleren også, tilpasses i ettertid. I «Texas sharpshooting» skytes det først på låveveggen, deretter tegnes målet opp rundt kulehullene [50]. Dette gjør at sannsynlighetsestimering spiller en helt annen rolle enn $i$ årsaksrettet forskning hvor hypotesene som testes er formulert a-priori.

Kvikksaken ble en sak som følge av en ekstraordinær observasjon av flere barn med misdannelser enn det man skulle forvente. Det synes imidlertid fortsatt å være uenighet om clusteret var tilfeldig, eller om det var kausalt som følge av en årsak som til nå ikke er identifisert. Ut fra dette synes det som om det omfattende arbeidet som ble nedlagt av MFR og andre ikke har bidratt til avgjørende avklaring. Kanskje kan en sosialantropologisk gjennomgang av Kvikksaken fra A til $\AA$ gi verdifull kunnskap for fremtidig håndtering av reaktive clustere.

\section{REFERANSER}

1. Irgens LM. Medisinsk fødselsregister - en hjørnesten i norsk epidemiologi. Norsk Epidemiologi $1997 ; 7$ (1): 5-10. doi: http://dx.doi.org/10.5324/nje.v7i1.346.

2. Irgens LM. The Medical Birth Registry of Norway. Epidemiological research and surveillance throughout 30 years. Acta Obstet Gynecol Scand 2000; 79 (6): 435-439. doi: 10.1034/j.1600-0412.2000.079006435.x.

3. Irgens LM. Registerbasert epidemiologisk forskning og forvaltning - et resultat av tilfeldighetenes spill eller en uunngåelig historisk utvikling? Norsk Epidemiologi 2007; 17 (2): 199-210.

4. Forskrift om innsamling og behandling av helseopplysninger i Medisinsk fødselsregister (Medisinsk fødselsregisterforskriften). Oslo: Helse- og omsorgsdepartementet, 2001. Tilgjengelig fra https://lovdata.no/dokument/SF/forskrift/2001-12-21-1483. 
5. Bjerkedal T, Bakketeig LS. Surveillance of congenital malformations and other conditions of the newborn. Int J Epidemiol 1975; 4 (1): 31-36.

6. Lie RT. Detecting changes in perinatal risks. Epidemiological studies based on the Medical Birth Registry of Norway, with implications for the methodology of surveillance of birth defects and other conditions in the new-born [Avhandling]. Bergen: Universitetet i Bergen, 1992.

7. EUROCAT (European Surveillance of Congenital Anomalies). http://www.eurocat-network.eu/.

8. Dolk H. EUROCAT: 25 years of European surveillance of congenital anomalies. Arch Dis Child Fetal Neonatal Ed 2005; 90 (5): F355-F358. doi: 10.1136/adc.2004.062810.

9. Whorton MD. Adverse reproductive outcomes: the occupational health issue of the 1980s [Editorial]. Am J Public Health 1983; 73 (1): 15-16. http://ajph.aphapublications.org/doi/pdf/10.2105/AJPH.73.1.15.

10. Lockey JE, Lemasters GK, Keye WR Jr., red. Reproduction: the New Frontier in Occupational and Environmental Health Research. New York: Alan R. Liss, 1984.

11. Stene-Larsen G. Medisinsk fødselsregister i forskning og forvaltning. Norsk Epidemiologi 2007 ; 17 (2): $95-$ 96. doi: http://dx.doi.org/10.5324/nje.v17i2.122.

12. Magnus P, Jaakkola JJK, Skrondal A, Alexander J, Becher G, Krogh T, Dybing E. Water chlorination and birth defects. Epidemiology 1999; 10 (5): 513-517.

13. Hwang B-F, Magnus P, Jaakkola JJK. Risk of specific birth defects in relation to chlorination and the amount of natural organic matter in the water supply. Am J Epidemiol 2002; 156 (4): 374-382..

14. Blaasaas KG, Tynes T, Lie RT. Residence near power lines and the risk of birth defects. Epidemiology 2003; 14 (1): 95-98.

15. Blaasaas KG, Tynes T, Lie RT. Risk of selected birth defects by maternal residence close to power lines during pregnancy. Occup Environ Med 2004; 61 (2): 174-176. doi: 10.1136/oem.2002.006239.

16. Irgens LM, Lie RT, Ulstein M, Skeie Jensen T, Skjærven R, Sivertsen F, Reitan JB, Strand F, Strand T, Skjeldestad FE. Pregnancy outcome in Norway after Chernobyl. Biomed Pharmacother. 1991; 45 (6): 233241. https://doi.org/10.1016/0753-3322(91)90023-M.

17. Lie RT, Irgens LM, Skjærven R, Reitan JB, Strand P, Strand T. Birth defects in Norway by levels of external and food-based exposure to radiation from Chernobyl. Am J Epidemiol 1992; 136 (4): 377-388.

18. Dolk H, Loane M, Teljeur C, Densem J, Greenlees R, McCullough N, Morris J, Nelen V, Bianchi F, Kelly A. Detection and investigation of temporal clusters of congenital anomalies in Europe: seven years of experience of the EUROCAT surveillance system. Eur J Epidemiol 2015; 30 (11): 1153-1164.

19. Lie RT. Studier av årsaker til medfødte misdannelser basert på Medisinsk fødselsregister. Norsk Epidemiologi 2007; 17 (2): 141-146. doi: http://dx.doi.org/10.5324/nje.v17i2.148.

20. Bjerkedal T. Yrke og fødsel. En undersøkelse over betydningen av kvinners yrkesaktivitet for opptreden av fosterskader. Rapport 80/9. Oslo-Kongsvinger: Statistisk Sentralbyrå, 1980. Tilgjengelig fra https://www.ssb.no/a/histstat/rapp/rapp 198009.pdf.

21. Irgens Å, Krüger K, Skorve AH, Irgens LM. Yrke og reproduksjonsutfall. En populasjonsbasert registerstudie, Norge 1970-1993. Utgave 3. Bergen: Yrkesmedisinsk avdeling, Haukeland sykehus - Medisinsk fødselsregister, Universitetet i Bergen, 1996. ISBN 82-7788-036-7.

22. EUROCAT (European Surveillance of Congenital Anomalies). Special report: an archive of the cluster advisory service content of the EUROCAT website. Newtownabbey: EUROCAT, 2014. Tilgjengelig fra http://www.eurocat-network.eu/content/Special-Report-CAS-with-Protocols.pdf.

23. Waage H, Magnus P. Undersøkelse av mulige årsaker til reduksjonsdeformiteter i Rana og Grenland. Rapport 2003:4. Oslo: Nasjonalt folkehelseinstitutt, 2003: 1-55. ISSN: 1503-1403, ISBN: 82-8082-032-9.

24. Heggland I, Irgens Å, Tollånes M, Romundstad P, Syversen T, Svendsen K, Melø I, Hilt B. Pregnancy outcomes among female dental personnel - a registry-based retrospective cohort study. Scand J Work Environ Health 2011; 37 (6): 539-546. doi:10.5271/sjweh.3175.

25. Dolk H, Lechat MF. Health Surveillance in Europe: Lessons from EUROCAT and Chernobyl. Int J Epidemiol 1993; 22 (3): 363-368. doi: https://doi.org/10.1093/ije/22.3.363.

26. Sjøforsvarets Forsyningskommando. Mulig sammenheng mellom høyfrekvente elektromagnetiske felt og medfødte misdannelser. SFK Rapport nr. 633-71331-100-002. SFK/T-TKK-EMC\&M. Bergen: SFK, 1998.

27. Irgens L, Lie RT, Baste V. Rapport om perinatale helseproblemer hos barn av tjenestegjørende i Sjøforsvaret. I: SFK. Mulig sammenheng mellom høyfrekvente elektromagnetiske felt og medfødte misdannelser. SFK Rapport nr. 633-71331-100-002. SFK/T-TKK-EMC\&M. Bergen: SFK, 1998: 507-534.

28. Irgens LM, Baste V, Wilk P, Halleraker JH, Lie RT. Clubfoot in offspring of servicemen in the Royal Norwegian Navy [Abstract]. International Clearinghouse for Birth Defects Monitoring Systems, $24^{\text {th }}$ annual meeting, Cape Town 19. November 1997. Teratology 1998; 57 (1):34.

29. Kristensen P, Jacobsen K, Skyberg K. Medfødte misdannelser blant barn med fedre som hadde tjeneste på KNM Kvikk. Stamirapport 3/2000. Oslo: Statens arbeidsmiljøinstitutt, 2000: 1-117. Tilgjengelig fra: https://brage.bibsys.no/xmlui/bitstream/handle/11250/288379/stamirapporter 35.pdf?sequence=1\&isAllowed=y. 
30. Baste V, Moen BE, Oftedal G, Strand LA, Bjørge L, Mild KH. Pregnancy outcomes after paternal radiofrequency field exposure aboard fast patrol boats. J Occup Environ Med 2012; 54 (4): 431-438.

31. Mjøen G, Sætre DO, Lie RT, Tynes T, Blaasaas KG, Hannevik M, Irgens LM. Paternal occupational exposure to radiofrequency electromagnetic fields and risk of adverse pregnancy outcome. Eur J Epidemiol $2006 ; 21$ (7): 529-535. doi: 10.1007/s10654-006-9030-0.

32. Moen BE, Baste V, Bondevik K, Haukenes I, Magerøy N. Sluttrapport fra prosjektet HMS Sjø. Rapport 2 2007. Bergen: Universitetet i Bergen, 2007: 1-23. Tilgjengelig fra http://www.uib.no/filearchive/sluttrapportfra-prosjektet.pdf.

33. Magerøy N, Baste V, Bondevik K, Haukenes I, Moen BE, Møllerløkken OJ, Riise T. En spørreundersøkelse om arbeid og helse blant ansatte i Sjøforsvaret. En delrapport i prosjektet HMS SJØ. Rapport nr. 1, 2004. Bergen: Universitetet i Bergen, 2004: 1-89. Tilgjengelig fra http://www.uib.no/filearchive/ensporreundersokelse-om-arbeid-og-helse-blant-ansatte-i-sjoforsvaret.pdf.

34. Baste V, Hansson Mild K, Moen BE. Radiofrequency exposure on fast patrol boats in the Royal Norwegian Navy - an approach to a dose assessment. Bioelectromagnetics 2010; 31 (5): 350-360.

35. Mageroy N, Mollerlokken OJ, Riise T, Koefoed V, Moen BE. A higher risk of congenital anomalies in the offspring of personnel who served aboard a Norwegian missile torpedo boat. Occup Environ Med 2006; 63:92-97. doi: 10.1136/oem.2005.021113.

36. Baste V, Riise T, Moen BE. Radiofrequency electromagnetic fields; male infertility and sex ratio of offspring. Eur J Epidemiol 2008; 23 (5): 369-377. doi: 10.1007/s10654-008-9236-4.

37. Møllerløkken OJ, Moen BE. Is fertility reduced among men exposed to radiofrequency fields in the Norwegian Navy? Bioelectromagnetics 2008; 29 (5): 345-352. doi: 10.1002/bem.20400.

38. Moen BE, Baste V, Møllerløkken OJ, Oftedal G, Mild KH. No evidence of adverse effects in reproductive health of women in the Navy who were exposed to radiofrequency electromagnetic fields. Maritime Medicine Journal 2014; 14 (1): 34-42.

39. Magnus P. Looking for effects of environmental contaminants in a large birth cohort: summarizing results of the Norwegian Mother and Child Cohort Study (MoBa). Int J Hyg Environ Health 2017; 220 (2): 71-76. doi: http://dx.doi.org/10.1016/j.ijheh.2016.12.011.

40. Akselsen A, Lien S, Siverstøl Ø. FD-Trygd: list of variables. Oslo-Kongsvinger: Statistics Norway, 2007. Tilgjengelig fra http://www.ssb.no/a/english/publikasjoner/pdf/doc 200705 en/doc 200705 en.pdf.

41. Kogevinas M, Sala M. Pesticides and congenital malformations - how many studies will it take to reach a conclusion? [Editorial]. Scand J Work Environ Health 1998; 24 (6): 445-447. doi:10.5271/sjweh.368.

42. Kristensen P, Irgens LM. Clusters of anophthalmia: no link with benomyl in Norway [Letter]. BMJ 1994; 308 (6922): 205-206. doi: https://doi.org/10.1136/bmj.308.6922.205c.

43. Forskrift om plantevernmidler. Oslo: Landbruks- og matdepartementet, 2015 . Tilgjengelig fra: https://lovdata.no/dokument/SF/forskrift/2015-05-06-455.

44. Miljødirektoratet. REACH kandidatlista (SVHC-lista). Tilgjengelig fra: http://miljødirektoratet.no/no/Tjenester-og-verktoy/Database/Kjemikalier/Kandidatlista-iREACH/?stoffListe $=104$.

45. Khoury MJ, Moore CA, James LM, Cordero JF. The interaction between dysmorphology and epidemiology: methodologic issues of lumping and splitting. Teratology 1992; 45 (2): 133-138.

46. Melve KK, Lie RT, Skjaerven R, Van Der Hagen CB, Gradek GA, Jonsrud C, Braathen GJ, Irgens LM. Registration of Down syndrome in the Medical Birth Registry of Norway: validity and time trends. Acta Obstet Gynecol Scand 2008; 87 (8): 824-30. doi: 10.1080/00016340802217184.

47. Carlsen E, Giwercman A, Keiding N, Skakkebaek NE. Evidence for decreasing quality of semen during past 50 years. BMJ 1992; 305 (6854): 609-613. doi: https://doi.org/10.1136/bmj.305.6854.609.

48. Joffe M. Invited commentary: the potential for monitoring of fecundity and the remaining challenges. Am $J$ Epidemiol 2003; 157 (2): 89-93. doi: https://doi.org/10.1093/aje/kwf177.

49. Olsen J, Rachootin P. Invited commentary: monitoring fecundity over time - if we do it, let's do it right. Am J Epidemiol 2003; 157 (2): 94-97. doi: https://doi.org/10.1093/aje/kwf178.

50. Rothman KJ. A sobering start for the cluster busters' conference. Am J Epidemiol 1990; 132 (Suppl 1): S6S13. doi: https://doi.org/10.1093/oxfordjournals.aje.a115790.

51. De Wals P. Investigation of clusters of adverse reproductive outcome, an overview. Eur J Epidemiol $1999 ; 15$ (9): 871-875. doi: 10.1023/A:1007638413985.

52. Sandman PM. Risk communication: facing public outrage. EPA Journal 1987; november: 21-22. Tilgjengelig fra: http://www.psandman.com/articles/facing.htm. 